\title{
Characterizing patient assistance program use and patient responsiveness to specialty drug price for multiple sclerosis in a mid-size integrated health system
}

\author{
Elizabeth Brouwer, PhD, MPH; Kai Yeung, PharmD, PhD; Douglas Barthold, PhD; and Ryan Hansen, PharmD, PhD
}

\section{What is already known about this subject}

- The increasing burden of specialty medication costs is causing payers to pass costs on to enrollees through evolving cost-sharing practices and increased premiums.

- The use of drug manufacturerprovided patient assistance programs (PAPs) to subsidize patient out-ofpocket spending is widespread, but its effect on consumer behavior for specialty drugs is poorly understood.

- Payers diverge in their treatment of PAPs, with some actively connecting patients to assistance programs and others enacting policies such as copay accumulator programs to penalize or prohibit patients from using assistance.

\author{
What this study adds \\ - A payer that embraced PAPs for \\ specialty drugs to reduce cost barriers \\ for patients succeeded in significantly \\ decreasing its patients' OOP costs to an \\ overall average of under $\$ 20$ per claim. \\ - PAPs were used more frequently at \\ the beginning of the year when OOP \\ charges were highest, and they almost \\ always covered $100 \%$ of a patient's \\ oOP cost. \\ - Access to OOP cost subsidization was \\ not associated with a change in patient \\ demand for multiple sclerosis drugs in \\ our study population, although there \\ was significant selection bias for those \\ with high OOP charges to seek financial \\ assistance.
}

\begin{abstract}
Author affiliations
Elizabeth Brouwer, PhD, MPH; Douglas Barthold, PhD; and Ryan Hansen, PharmD, PhD, Department of Pharmacy, University of Washington, Seattle. Kai Yeung, PharmD, $\mathrm{PhD}$, Kaiser Permanente Washington Research Institute, Seattle.
\end{abstract}

AUTHOR CORRESPONDENCE: Elizabeth Brouwer, 734.709.6817; ebrouwer@uw.edu

J Manag Care Spec Pharm 2021;27(6):732-42

Copyright $\odot 2021$, Academy of Managed Care Pharmacy. All rights reserved.

the second part estimated days supplied of a medication, given a claim was made as a measure for demand.

RESULTS: Of 789 unique patients, 480 (60.7\%) used PAPs in at least 1 drug claim during the 13-month time frame, and 248 patients (31.4\%) used PAPs for all of their MS drug claims. When used, copay assistance covered $100 \%$ of out-of-pocket (OOP) charges for $98 \%$ of claims and reduced patient annual OOP cost by $\$ 3,493$ on average. People who used PAPs had much higher OOP charges, a lower Charlson comorbidity score, and were more likely to have insurance through an exchange. The OOP costs charged to patients 
was higher for claims where patient assistance was used than claims where assistance was not used ( $\$ 294$ vs $\$ 42, P<0.001$ ). Total claim amount was higher for claims that used assistance $(\$ 6,169)$ than claims that did not $(\$ 5,503, P<0.001)$. The probability of a patient having a drug claim in a given month was $1.9 \%$ higher among those using patient assistance, although this finding was not significant $(P=0.258)$. An average change in price of $-\$ 168.21$ with PAP use led to an average change in demand of -0.05 days, for an overall price elasticity of demand $(S D=0.028, P=0.852$ ) given PAP use of 0.005 , indicating that the presence of PAPs did not significantly affect demand. PED estimates were not statistically significant by drug, and the exclusion of Medicare patients did not change this interpretation.

CONCLUSIONS: In a mid-size integrated health system in the state of Washington, a program that promotes adherence to specialty drugs via facilitated PAP use was found to reduce patient OOP costs but had no effect on prescription drug utilization. Payers may consider embracing PAPs to remove patient financial barriers to necessary medications and use tools other than cost sharing to influence patient consumption of specialty drugs.
There is an ongoing public conversation about patient drug costs in the United States and how those costs can affect patient access and adherence to necessary medication. ${ }^{1}$ The specific concern is that out-of-pocket (OOP) costs are too high, disincentivizing optimal medication use through lowered adherence, skipped prescriptions, or discontinued use..$^{1,2}$

A significant omission in this conversation, however, is manufacturer-provided patient OOP assistance, also referred to as copay coupons or as patient assistance programs (PAPs). A practice that emerged in the mid-2000s, PAPs are defined as a drug manufacturer paying for some or all of a patient's OOP charges at the point of sale..$^{3,4}$ The use of PAPs can be suggested by a physician if a patient has concerns about covering a drug cost or patients can learn about discount programs via television commercials, online advertisements, or search engine results, and redemption materials can be printed out online, sent in the mail, or requested at the pharmacy.

The use of PAPs can be difficult to track, however, and their use is generally omitted from claims analysis. ${ }^{5}$ One source with access to PAP data found that the practice is growing in prevalence and, in 2018, was used in an estimated $18 \%$ of all branded prescriptions and $42 \%$ of all specialty prescriptions. ${ }^{6}$ Another study estimated that $46 \%$ of claims for specialty drugs treating multiple sclerosis (MS) used PAPs, producing an average $61 \%$ reduction in OOP charges. $^{7}$
Despite the growth in PAPs, there is no broad consensus regarding the practice's overall impact on pharmaceutical access and costs. Some argue that the practice is necessary for patients to be able to afford their clinically necessary medication, particularly if there is no generic or less costly alternative. ${ }^{8}$ PAPs may also serve to undercut insurance levers meant to steer patients toward payers' preferred therapeutic alternatives, which would ultimately increase payer costs and potentially increase patient costs through other channels, such as raised premiums..$^{9,10}$

Kaiser Permanente Washington (KPWA), a US integrated managed care organization, has embraced the practice through a specialty pharmacy disease management program that actively promotes adherence to medication and helps patients to obtain PAP reimbursement. ${ }^{11}$ Given the growing use and prices of specialty drugs, and the relatively opaque nature of PAPs, our research goal was to characterize the use of PAPs in this specialty drug program and to estimate patient price elasticity of demand (PED) for those medications using patient assistance as a source of price variation. We focused on specialty drugs indicated for MS.

\section{Methods}

We describe trends from 13 months of observational, crosssectional, pharmacy claims data for 7 unique molecules used to treat MS (10 branded drugs). We also used a two-part model to estimate the demand for MS drugs and calculated the PED associated with patient assistance-based price variation. All analyses were performed using Stata version 15.1 (StataCorp), with institutional review board approval from the University of Washington and Kaiser Permanente Washington.

\section{DATA}

Claims data came from the KPWA system, a large health maintenance organization serving over 700,000 patients in the state of Washington. All claims for MS drugs, as defined by their National Drug Code numbers, that fell between December 1, 2017, and December 31, 2018, were included in the initial dataset, excluding patients under age 18 years, patients using Medicaid as their primary payer, and patients without 6 months of continuous enrollment before their first claim. We included all drugs indicated for MS on the Kaiser Washington drug formulary during the time period (Table 1), which resulted in 7,465 prescription claims for 789 individuals. We studied MS drugs over 13 months (December 2017-December 2018) when secondary payer information was available. We focused on MS and omitted other types of specialty drugs, such as anti-inflammatory medications, 


\begin{tabular}{|c|c|c|c|c|}
\hline $\begin{array}{c}\text { Brand name } \\
\text { (generic name, administration) }\end{array}$ & $\begin{array}{l}\text { Number of claims } \\
\text { (\% of total) }\end{array}$ & $\begin{array}{l}\text { Difference in average } \\
\text { OOP charge } \\
\text { (PAP users-nonusers) }^{\text {a }} \\
\text { Difference (SD) }\end{array}$ & $\begin{array}{l}\text { PAP users } \\
\text { N (\%) }\end{array}$ & $\begin{array}{l}\text { Average PAP amount } \\
\text { (if used) } \\
\text { \$(SD) }\end{array}$ \\
\hline Total (all drugs) & $7,465(100.0)$ & $\$ 276.76 \quad(11.1)$ & $3,889 \quad(52)$ & $\$ 305.19 \quad(673.22)$ \\
\hline Aubagio (teriflunomide, oral) & $196 \quad(2.6)$ & $\$ 197.56 \quad(40.2)$ & $126(64)$ & $\$ 194.18 \quad(434.77)$ \\
\hline Avonex $^{\mathrm{b}}$ (interferon beta-1a, IM) & $1,383 \quad(18.5)$ & $\$ 255.75 \quad(27.7)$ & $598 \quad(43)$ & $\$ 294.31 \quad(671.49)$ \\
\hline Betaseron (interferon beta-1b, SC) & $51 \quad(0.7)$ & $\$ 154.71 \quad(19.0)$ & $36(71)$ & $\$ 166.50 \quad(122.73)$ \\
\hline Copaxone (glatiramer acetate, SC) & $(3.5)$ & $\$ 404.39 \quad(69.2)$ & 128 (49) & $\$ 415.58 \quad(699.43)$ \\
\hline Extavia $^{\mathrm{b}}$ (interferon beta-1b, SC) & $(5.6)$ & $\$ 315.77 \quad(48.5)$ & $235 \quad(56)$ & $\$ 327.57 \quad(742.97)$ \\
\hline Gilenya (fingolimod, oral) & $1,433 \quad(19.2)$ & $\$ 171.56 \quad(21.4)$ & $931 \quad(65)$ & $\$ 206.18 \quad(633.61)$ \\
\hline 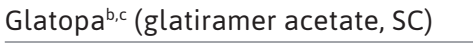 & $1,586 \quad(21.3)$ & $\$ 390.34 \quad(26.8)$ & $557 \quad(35)$ & $\$ 412.17 \quad(621.35)$ \\
\hline Plegridy (peginterferon beta- $1 \mathrm{a}, \mathrm{SC}$ ) & $(0.3)$ & $\$ 48.35 \quad(7.9)$ & $6(32)$ & $\$ 60.71 \quad(11.07)$ \\
\hline Rebif ${ }^{b}$ (interferon beta-1a, SC) & $(7.3)$ & $\$ 231.12 \quad(37.7)$ & $396(73)$ & $\$ 254.94 \quad(745.56)$ \\
\hline Tecfidera (dimethyl fumerate, oral) & $1,572 \quad(21.1)$ & $\$ 341.80 \quad(24.9)$ & $876 \quad(56)$ & $\$ 373.73$ (713.17) \\
\hline \multicolumn{5}{|c|}{$\begin{array}{l}\text { Notes: All cost data in } 2018 \text { USD. Total number of claims excludes imputed data (months with no claim). } \\
\text { aStandardized to a 30-day supply. }\end{array}$} \\
\hline
\end{tabular}

because the type of patient assistance for those drugs (prepaid debit cards) was not observable in our data. ${ }^{5}$

Financial data included the amount initially charged to the patient, whether there was patient assistance, and the amount the patient paid after accounting for patient assistance. All cost data are reported in 2018 US dollars. Patient-level data included age range, sex, insurance type, medication possession ratio (MPR) and Charlson Comorbidity Index score. We estimated adherence at the patient level by calculating each patient's MPR over the 13 months of available data. MPR was calculated using dispense date and days supplied for each relevant patient-drug combination over the course of patient enrollment captured in the dataset.

The Charlson Comorbidity Index score was calculated using the most recent 12 months of continuous enrollment data before the study's start for each patient using the method developed by Quan et al in 2011..$^{12}$ To supplement claims data, we linked county of residence with demographic indicators (median income and percentage of population that was non-White) produced by the Washington State Office of Financial Management. ${ }^{13}$ Descriptive statistics were derived at the claim and patient levels.

\section{DEFINING PAP USE}

We defined a claim as using a PAP if it had a secondary payer (an entity other than the patient's primary insurer) paying a nonzero amount toward the patient's OOP amount. Claims with secondary payers in the form of additional insurance, however, such as Kaiser Permanente financial assistance or Medicare Part D, were not defined as using a PAP and the charged OOP amount for those claims was defined as the OOP amount after accounting for all insurance contributions.

\section{DRUGS CONSIDERED}

We analyzed 10 unique branded drugs (7 unique molecules; generic names: dimethyl fumerate, fingolimod, glatiramer acetate, interferon beta-1a, interferon beta- $1 \mathrm{~b}$, peginterferon beta-1a, and teriflunomide; brand names available in Table 1) indicated for MS treatment. Because insurers negotiate and set their formularies for specific brands of drugs, we performed analyses and displayed results at the singlesource brand-name level.

\section{CREATING A FULL PANEL AND DATA IMPUTATION}

Data were collapsed to the patient-drug-month level by taking the sum of costs and days supplied for any patient claim for a single drug during a calendar month. After an 
individual's first observed fill for a given drug, any subsequent months without an observed fill were assumed to have 0 days supplied, resulting in a full panel of 13 data points for each patient. In the patient-months with 0 days supplied, we carried forward the patient and drug characteristics from the months in which patients made claims for the same individual and drug; no patients in our dataset used more than 1 drug during the 13 months, so we could assume drug characteristics based on that patient's other claims. In months with greater than 31 days supplied, the subsequent month was assumed to carry over the extra days from the previous month; in those cases, the imputed month was dropped.

We performed multiple imputation by chained equations to estimate the 2 claim-specific variables that were unable to be carried forward for the months in which a patient did not make a claim: what the OOP charge would have been and whether a PAP would have been used. The multiple imputation by chained equations used existing data from that patient's other claims and claims for the same drug in the same month from similar patients to estimate plausible values for hypothetical amounts while maintaining realistic variability in the dataset. We used 10 iterations of predictive mean matching from 500 nearest neighbors for each of the 2 imputed variables. Predictive mean matching was the most appropriate way to impute plausible values for the observations, given the continuous but non-normal cost variable with a large number of zeros. ${ }^{14}$ Matches were based on month, drug, age, sex, ZIP code characteristics, and Charlson Comorbidity Index scores.

\section{TWO-PART OUTCOME MODEL}

$$
\begin{gathered}
\text { First Part } \\
\mathrm{P}(\mathrm{Q}>0)=\mathrm{B}_{1} \times \text { OOP Charge }+\mathrm{B}_{2} \times \text { PAP Indicator }+\mathrm{B}_{\mathrm{X}} \times \mathrm{X}+\varepsilon \\
(\text { Eq. } 1) \\
\text { Second Part } \\
\mathrm{E}(\mathrm{Q} \mid \mathrm{Q}>0)=\mathrm{B}_{1} \times \text { OOP Charge }+\mathrm{B}_{2} \times \text { PAP Indicator }+\mathrm{B}_{\mathrm{X}} \times \mathrm{X}+\varepsilon
\end{gathered}
$$

We used a probit model in the first part of the twopart model to estimate the probability of any claim in the patient-drug-month, controlling for age; sex; binary indicator of Charlson Comorbidity Index score of 1 or more based on the previous 12 months of medical claims data; drug and month fixed effects; insurance type (eg, health care exchange, employer-based, and Medicare); drug administration method; and county-level demographics (Equation 1). Standard errors were clustered at the patient level. The independent variables of interest in the first part of the main model were OOP charge and a binary indicator of patient assistance.
We then ran a zero-truncated negative binomial model with standard errors clustered at the patient level to estimate the days supplied of the drug, given that there was a claim in that month (Equation 2). This model had the same independent variables of interest and controls as the probit model, with the added variables of whether the claim was via mail order and whether the claim was a patient's first prescription fill. Total quantity demanded was a product of the estimated outcomes from both parts of the model. The two-part model was run on the empirical data to estimate factual demand, and then the same model coefficients were used to estimate counterfactual predictions, given patient assistance set to zero.

\section{PED ESTIMATION}

$$
\begin{gathered}
\text { Price Elasticity } \\
\text { of Demand }
\end{gathered}=\frac{\% \Delta \text { Quantity }}{\% \Delta \text { Price }}=\frac{\left(\mathrm{Q}_{1}-\mathrm{Q}_{2} / \overline{\mathrm{Q}}\right)}{\left(\mathrm{P}_{1}-\mathrm{P}_{2} / \bar{p}\right)}
$$

We used recycled predictions in the two-part model to estimate the change in quantity demanded due to copay assistance (Equation 3). ${ }^{15}$ After estimating the quantity demanded in the data (Q1), we set the PAP indicator variable to zero and estimated the quantity demanded within the model if no one had copay assistance (Q2). This informed our change in quantity demanded and the mid-point quantity demanded (Q-bar). The change in price (P1-P2) was the copay assistance amount, where the mean price (P-bar) was the mid-point between the pre- and post-copay assistance amounts. These elements, estimated for each line of data, informed our average price elasticity of demand equation.

This exercise was completed for the entire dataset, as well as on subsets of data for each individual drug, with the results interpreted as the association of PAP amount and drug demand. We bootstrapped with 1,000 iterations to estimate CIs and $\mathrm{P}$ values for price elasticity estimates by drug and overall. We anticipated potential issues with lack of variation in the days supplied of prescription fills and therefore we also report the marginal effect of patient assistance on the probability of getting any claim from the first part of the two-part model as an additional source of information about patient behavior.

\section{SENSITIVITY ANALYSIS}

Our measure of demand was existence of any claim in a drug-patient-month and then days supplied, given that a claim existed. Other analyses have used prescription abandonment, initiation, discontinuation, number of claims, and drug spending as measures of demand. ${ }^{16}$ Because of data 
limitations, we were unable to consider drug initiation or prescription abandonment as measures of demand. To investigate the effect of model specification on our results, we ran a sensitivity analysis that included the PAP indicator, OOP charge, and their interaction to capture differences in patient response to price change given the presence of patient assistance. While we did not include the interaction term in our main analysis due to the potential for bias from collinearity, we believe it is a useful sensitivity analysis to test the validity of our results. In addition, we noted that certain types of PAPs are legally prohibited within federal health insurance plans, such as Medicare, because of a federal anti-kickback statute. ${ }^{17}$ To assess whether the inclusion of Medicare patients in the analysis impacted our results, we ran a sensitivity analysis excluding all Medicare claims.

\section{Results}

\section{SAMPLE DESCRIPTION}

Our sample of claims for MS drugs during December 1, 2017, to December 31, 2018, included 789 unique patients and 7,465 claims (Table 2). Of the 789 patients in the sample, 550 unique patients (69.6\%) used some sort of secondary payer to cover their OOP responsibility. The majority of claims with secondary assistance were PAPs (92\%); however, patients also received OOP assistance from Kaiser's financial assistance program (8\%) and secondary insurance such as Medicare Part D and Medicaid (1\%).

\section{CHARACTERIZATION OF PATIENT ASSISTANCE}

Of the entire sample, 531 patients (67.2\%) used manufacturer-provided PAPs for at least 1 claim during the time period of 13 months. Those who used a PAP at least once during the year varied in their consistency of patient assistance use. The slight majority of patients using PAPs (51.7\%) used them for every pharmacy claim. Less than a quarter of the patients (22.3\%) used PAPs for less than half of their pharmacy claims, while $26 \%$ used PAPs for more than half but not all of their claims.

People who used PAPs had, on average, less comorbidities as measured by the Charlson Comorbidity Index and were more likely to use a drug via subcutaneous injection than via oral or intramuscular injection administration (Table 2). They were also more likely to have insurance through the state of Washington's health care exchange. There was no significant association between PAP use and age, sex, drug adherence as measured by MPR, or in the median income or racial makeup of the counties where patients lived. PAP use was highest in January and tapered off throughout the year, mirroring trends in the magnitude of OOP charges over the year (Figure 1).

Patients who used any PAP had higher average total costs per claim (\$6,169 vs $\$ 5,504)$ and higher OOP charges (the amount charged to the patient before any secondary payer assistance is applied; \$294 vs \$42), but lower final OOP costs (the amount the patient ultimately paid for a claim; \$7 vs \$42) than their counterparts who did not use PAPs (Table 2). Copay assistance covered $100 \%$ of OOP costs for $98 \%$ of claims using them. When considered for a year's supply of medication, total claims per patient using PAPs were $\$ 5,283$ more than those not using PAPs ( $\$ 71,483$ vs $\$ 66,200$ ), not adjusting for other characteristics or accounting for rebates. Patient assistance also reduced patient actual OOP costs by $\$ 3,494$ annually compared with non-PAP users.

\section{PAPS AMONG SPECIFIC DRUGS}

Approximately $80 \%$ of patients used 1 of 4 drugs: interferon beta-1a (intramuscular administration), fingolimod, glatiramer acetate (branded version), and dimethyl fumarate (Table 1). For each drug, the OOP charge for PAP users was higher than the OOP charge for non-PAP users, indicating PAP use was associated with higher OOP charges. Some drugs were associated with higher PAP use, however, including teriflunomide, interferon beta- $1 \mathrm{~b}$, fingolimod, interferon beta-1a (subcutaneous administration), and dimethyl fumarate. The remaining drugs (interferon beta1a (intramuscular administration), glatiramer acetate, and peginterferon beta-1a) had more claims without PAP use than with PAP use. Higher PAP usage did not appear to be associated with a brand's preferred status on the Kaiser formulary or average PAP amount (Table 1).

\section{PRICE ELASTICITY OF DEMAND}

The results from the first part of the two-part model are reported in Table 3. The dataset originally included 7,063 person-drug months, which expanded by 3,532 observations to fill the panel for all months; 182 observations were dropped following months with greater than 31 days of medicine supplied. PAP users had a 1.9\% higher probability of filling a claim than non-PAP users, although this was not significant (95\% CI: $-1.4 \%, 5.2 \%)$. This result did not change in significance when including an interaction term between PAP use and OOP charge $(1.65 \%, 95 \%$ CI: $-1.6 \%$, $4.9 \%)$. This effect was further attenuated in the second part of the model.

The absence of patient assistance for a prescription fill in our sample was associated with an average \$168 increase in patient cost and a decrease of 0.05 days in demand, which translated to a price elasticity of 0.005 (95\% CI: $-0.05,0.06)$. While point estimates for PED varied by drug, none of the 


\section{TABLE 2 Characteristics by Use of Patient Assistance Programs}

\begin{tabular}{|c|c|c|c|c|}
\hline At person level & $\begin{array}{c}\text { No patient assistance } \\
(n=258)\end{array}$ & $\begin{array}{l}\geq 1 \text { claim with patient } \\
\text { assistance }(n=531)\end{array}$ & $\begin{array}{c}\text { Overall sample } \\
(n=789)\end{array}$ & $\begin{array}{c}\text { Significance }^{a} \\
(P \text { value })\end{array}$ \\
\hline Number of claims per patient & 8.78 & 9.79 & 9.46 & 0.002 \\
\hline Age ranges, $\mathrm{n}(\%)$ & & & & 0.102 \\
\hline $18-39$ & $30 \quad(11.6)$ & $89 \quad(16.8)$ & $119 \quad(15.1)$ & \\
\hline $40-59$ & $139 \quad(53.9)$ & $301 \quad(56.7)$ & $440 \quad(55.8)$ & \\
\hline $60+$ & $89 \quad(34.5)$ & $141 \quad(26.6)$ & $230 \quad(29.1)$ & \\
\hline \multicolumn{5}{|l|}{ Sex } \\
\hline Male, n (\%) & $70 \quad(27.1)$ & $130 \quad(24.5)$ & $200 \quad(25.3)$ & 0.422 \\
\hline Female, n (\%) & $188 \quad(72.9)$ & $401 \quad(75.5)$ & $589 \quad(74.7)$ & \\
\hline Charlson comorbidity score >1, n (\%) & $94 \quad(36.4)$ & $140 \quad(26.4)$ & $234 \quad(29.7)$ & 0.004 \\
\hline Medication possession ratio ${ }^{\mathrm{b}}$ & 0.927 & 0.935 & 0.932 & 0.446 \\
\hline Using intramuscular route, $\mathrm{n}(\%)$ & $62 \quad(23.9)$ & $70 \quad(13.1)$ & $131 \quad(16.6)$ & $<0.001$ \\
\hline Using oral route, $\mathrm{n}(\%)$ & $71 \quad(27.5)$ & $249 \quad(46.9)$ & $320 \quad(40.6)$ & $<0.001$ \\
\hline Using subcutaneous route, $\mathrm{n}(\%)$ & 125 (48.6) & $212 \quad(39.9)$ & $337 \quad(42.8)$ & 0.020 \\
\hline Insurance groups, n (\%) & & & & $<0.001$ \\
\hline Employer-sponsored insurance & $207 \quad(80.2)$ & $378 \quad(71.2)$ & $585 \quad(74.1)$ & \\
\hline Health insurance exchange & $11 \quad(4.3)$ & $101 \quad(19.0)$ & $112 \quad(14.2)$ & \\
\hline Other (including Medicare Part D) & $40 \quad(15.5)$ & $51 \quad(9.6)$ & $91 \quad(11.5)$ & \\
\hline Non-White (county level), ${ }^{\complement} \mathrm{n}(\%)$ & $78 \quad(30.3)$ & $151 \quad(29.7)$ & $227 \quad(29.9)$ & 0.373 \\
\hline Median income (county level)c & $\$ 75,028$ & $\$ 74,421$ & $\$ 74,622$ & 0.575 \\
\hline At person-drug-month level & No patient assistance & Used patient assistance & Overall sample & $\begin{array}{c}\text { Significance } \\
\text { (P value) }\end{array}$ \\
\hline Average total claim amount ${ }^{\mathrm{d}}(\mathrm{SD})$ & $\$ 5,503.66 \quad(1,813)$ & $\$ 6,168.68 \quad(1,561)$ & $\$ 5,951.22 \quad(1,676)$ & $<0.001$ \\
\hline Average OOP charged to patient ${ }^{\mathrm{d}}(\mathrm{SD})$ & $\$ 42.35 \quad(169)$ & $\$ 294.48$ & $\$ 212.04$ & $<0.001$ \\
\hline Average OOP paid by patient ${ }^{\mathrm{d}}$ (SD) & $\$ 42.35$ & $(57.8)$ & $\$ 18.71$ & $<0.001$ \\
\hline Annual total claims amount (SD) & $\$ 66,200.05(22,060)$ & $\$ 71,482.58(20,248)$ & $\$ 69,755.21(20,991)$ & 0.001 \\
\hline Annual OOP savings per patient ${ }^{\mathrm{e}}$ & $\$ 0.00$ & $\$ 3,493.56$ & $\$ 2,351.18$ & $<0.001$ \\
\hline
\end{tabular}

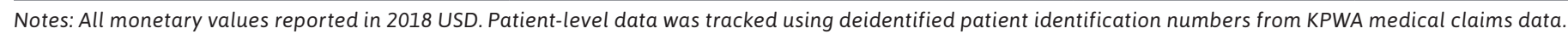
asignificance determined via t-test or chi-square test.

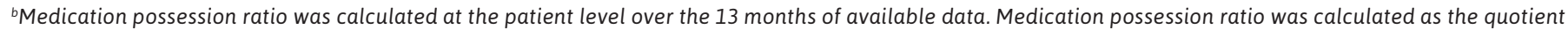
of days of medication supplied and days between first claim and end of coverage of the last claim at the patient level for the entirety of the year analyzed.

cMedian income and \% non-White data from Washington State Office of Financial Management $2018 .{ }^{12}$

'Standardized to a 30-day claim using days supplied

${ }^{e}$ Annual costs calculated at the claim level by dividing the cost by days supplied and multiplying the result by 365.25 days.

$K P W A=$ Kaiser Permanente Washington; OOP = out of pocket; USD = US dollars.

estimates were statistically different from zero (Table 4). The average changes in patient cost by drug (\$24-\$216) in the absence of patient assistance were statistically significant; however, the average change in quantity demanded, as measured by days supply given that a claim is present, was not different from zero for any drug or overall. Excluding Medicare patients from the sample did not change these results (Supplementary Table 1, available in online article)

\section{Discussion}

Although PAPs are prevalent for high-priced pharmaceuticals, their impact on utilization and spending are not well understood. With data from KPWA patients using drugs for MS during the period from 2017 to 2018, we assessed patterns in PAP use and whether they were associated with medication demand. We found that patients within a 


\section{FIGURE 1 OOP Charges and Patient Assistance Amounts by Month}

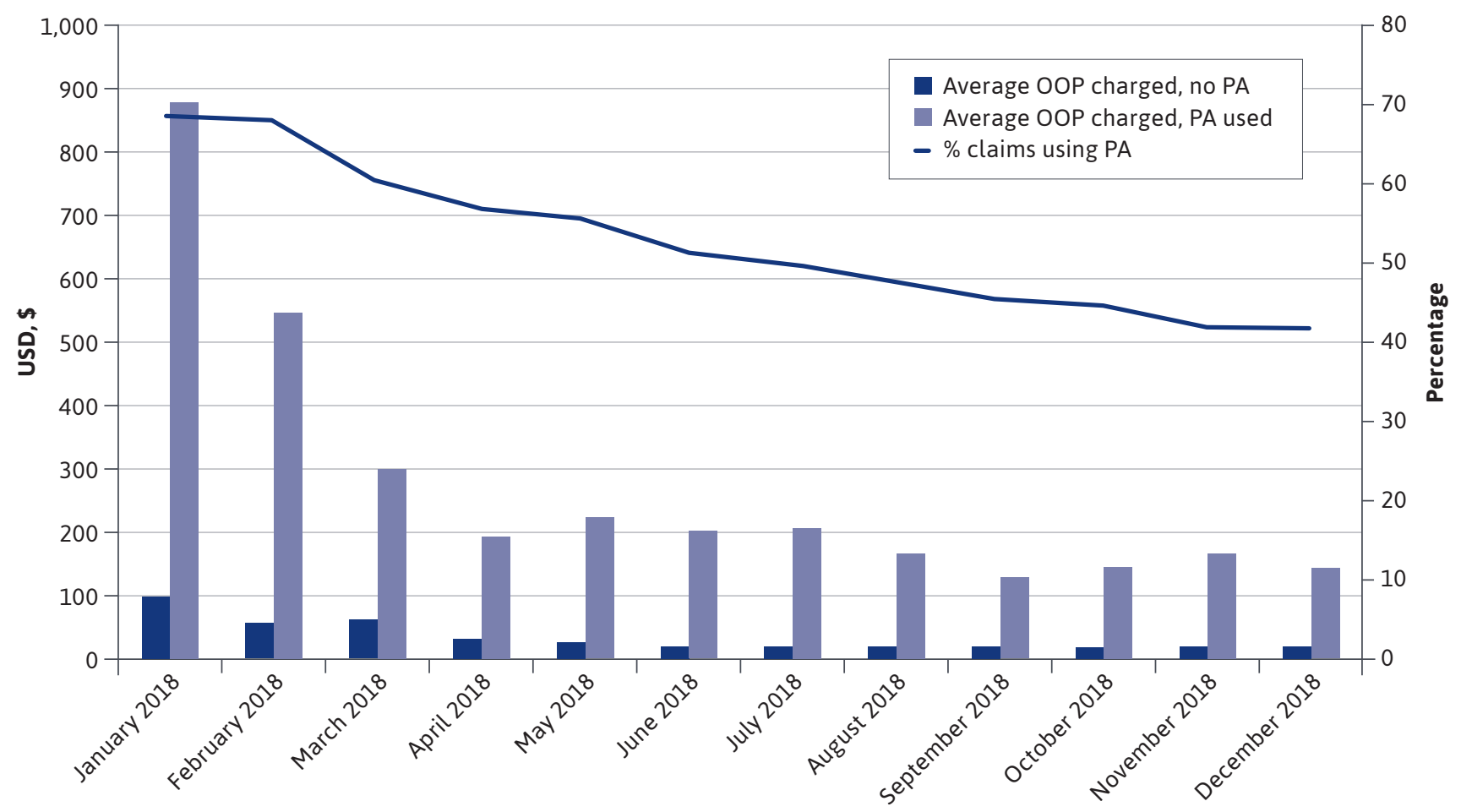

Notes: All data from KPWA from January 2018-December 2018; cost data in 2018 USD. Percent claims using PAPS calculated at the month level using the date the claim was picked up. Patient assistance use defined as secondary payer assistance from a noninsurance or charity source. Average OOP charged defined as the patient's financial responsibility for a claim, as charged by KPWA before applying any manufacturer financial assistance.

$K P W A=$ Kaiser Permanente Washington; $O O P=$ out of pocket; $P A=$ patient assistance; $P A P=$ patient assistance program; USD=US dollar.

specialty pharmacy program that promotes PAP use had very low OOP payments (average actual OOP cost for all patients $<$ \$20). Our findings suggest that this PAP use was not associated with a change in demand for drugs because underlying adherence rates were very high and potential selection may have biased results toward the null.

The results in this study population differ from other study populations that found high OOP costs of specialty drugs, using datasets without visibility into PAPs..$^{18,19}$ Our results indicate that OOP costs for specialty drugs may be very low depending on payer policy toward patient assistance. This may be clinically encouraging, since patients with less than \$250 copay are less likely to abandon therapy. ${ }^{7,20}$ However, our study provides evidence that such generosity is associated with higher payer costs, potentially because of switching to more costly medications. ${ }^{11}$ It is also possible that a generous specialty pharmacy program would increase costs because of adverse selection in their patient population, with more costly enrollees attracted by the sanctioned use of PAPs.

Our analysis found that patient demand for MS specialty medication did not change significantly, given the availability of PAPs. There are several likely reasons for this to be the case. Foremost, in the data we saw that there was strong selection bias for those with high OOP charges to seek a PAP. Therefore, annual patient medication costs seen in this dataset did not approach previously identified inflection points for prescription abandonment. ${ }^{21}$ Further, because of the severity of their conditions, patients have strong incentive to be adherent if prices stay within a reasonably affordable range. ${ }^{22}$ In addition, this patient population had a high baseline adherence level potentially because of the KPWA disease management program. ${ }^{11}$

Previous research on PAPs used for specialty drugs helps put our research into context. A study using similar techniques to link pharmacy sales data to claims in order to identify PAP use among patients with MS during a single 


\section{TABLE 3}

\section{Probability
Assistance}

\begin{tabular}{l|c|c|c|c}
\hline $\begin{array}{c}\text { Probit model: Specification of } \\
\text { independent variables of interest }^{\mathrm{a}}\end{array}$ & $\begin{array}{c}\text { Difference } \\
\text { in predicted } \\
\text { probability of } \\
\text { a claim } \\
(\mathbf{n}=\mathbf{7 , 4 6 5 )}\end{array}$ & $\begin{array}{c}\text { Standard } \\
\text { error }^{\mathbf{b}}\end{array}$ & P value $^{\mathbf{c}}$ & $\mathbf{9 5 \%} \mathbf{C l}$ \\
\hline Model 1: No interaction term $^{\mathrm{d}}$ & $1.90 \%$ & 0.0168 & 0.258 & $-1.39 \%, 5.18 \%$ \\
\hline Model 2: Includes interaction term & $1.65 \%$ & 0.0167 & 0.321 & $-1.61 \%, 4.92 \%$ \\
\hline
\end{tabular}

Notes: Positive value indicates higher probability of a claim given patient assistance. Outcomes are the result of running a probit model on the probability of a patient getting a claim, given their OOP charge, patient assistance, and control variables, with standard errors clustered at the patient level. Differences in predicted probability of a claim calculated using the margins command in Stata version 15 over the variable for whether a PAP was used.

${ }^{a}$ All probit model specifications contained the same control variables described in the text.

${ }^{b}$ Standard error by delta method.

c $P$ value based on chi-square test for the PAP indicator variable with 1 degree of freedom.

dModel $1=P A P$ indicator and OOP charged as individual variables.

'Model $2=P A P$ indicator, OOP charged, PAP indicator ${ }^{\star} O O P$ charged, included individually and with interaction term.

$P A P=$ patient assistance program; $O O P=$ out of pocket

year (2013) found comparable OOP charges and plan costs per claim. ${ }^{7}$ Our findings from 5 years later indicate that at KPWA the number of patients using PAPs for MS has increased from $46 \%$ to $60 \%$ and that PAPs are now covering the entirety of patient costs as opposed to an average $61 \%$ of an OOP charge. PAP use in other therapeutic areas may be less extensive; a study from 2013-2015 found that PAPs for oral cancer medications were only used in $12 \%$ of prescriptions, for which they covered less than $25 \%$ of the price charged. ${ }^{23}$

In light of this, insurers may need to reconsider cost-sharing formulary policies for specialty drugs. Patients in this cohort, when seeking aid, were able to get $100 \%$ of their cost-sharing responsibility paid for by drug manufacturers, effectively negating cost sharing as a behavior modifier and instead making it effectively another form of reimbursement from manufacturers. Without cost sharing to influence patient decisions, insurers would need to rely more heavily on other management techniques, such as prior authorization, step therapy, preferred status in clinical guidelines, and formulary exclusion, in order to direct patient behavior.

Alternately, as a reaction to PAPs, many health plans have instituted copay accumulator programs, which prevent payments from PAPs from being applied to patient deductibles. ${ }^{24}$ Therefore, when patients reach PAP limits, they are still responsible for the majority of their deductible. While copay accumulator programs may reduce plan spending, there is a concern that such tools may also adversely impact adherence.

This study also provides evidence that patients with insurance similar to KPWA may be almost completely insulated from their medication costs and accompanying price increases. Past work at KPWA found that although disease management programs in MS increased payer costs through increased adherence and patient use of more expensive drugs, a significant portion of increased costs was attributable to drug price inflation for patients who did not switch medications. ${ }^{11}$ Other studies have found that a majority of PAPs are for therapies where a generic equivalent exists and that PAPs increase branded drug use over generic drug use.,25 Current state laws in Massachusetts and California have tried to address this issue by banning PAPs only for drugs with generic equivalents. For drugs without generic alternatives, however, PAPs mask annual price increases, which can be substantial for specialty drugs. ${ }^{8,26}$ Future research should investigate the effect of PAPs on price inflation for drugs with no generic substitutes.

\section{LIMITATIONS}

Our study should be interpreted with the following limitations in mind. It cannot be assumed that our results are generalizable to other patient populations; rather, our results provide insight into the potential outcomes of specialty drug programs that promote PAP use.

The fact that our dataset derived from a program that embraced PAPs also led to selection bias within our data. We used coupon use as a source of price variation to calculate our price elasticity estimates; however, that variation was not randomly distributed among patients. Most patients with higher OOP charges used patient assistance, so we did not have adequate data to predict patient behavior in the face of high OOP charges without patient assistance. This likely biased our PED estimates toward the null. Our PED estimates, therefore, were not calculated using demand variation that was necessarily caused by price variation.

It is also difficult to generalize claims analysis for specialty drugs, since many of these medications are administered intravenously and can 


\section{TABLE 4 Price Elasticity of Demand by Brand}

\begin{tabular}{|c|c|c|c|c|c|c|c|c|c|c|}
\hline $\begin{array}{c}\text { Brand name (generic name, } \\
\text { administration) }\end{array}$ & $\begin{array}{c}\text { Number } \\
\text { of } \\
\text { person- } \\
\text { months, } \\
n\end{array}$ & $\begin{array}{c}\text { Mean } \\
\text { change } \\
\text { in } \\
\text { demand } \\
\text { (days } \\
\text { supplied } \\
\text { given a } \\
\text { claim) }\end{array}$ & $\begin{array}{c}\text { SD } \\
\text { ( } P \text { value })\end{array}$ & $95 \% \mathrm{Cl}$ & $\begin{array}{c}\text { Mean } \\
\text { change } \\
\text { in price }\end{array}$ & $\begin{array}{c}\text { SD } \\
\text { ( } P \text { value })\end{array}$ & $95 \% \mathrm{Cl}$ & $\begin{array}{c}\text { Mean } \\
\text { PED } \\
\text { given } \\
\text { PAP use }\end{array}$ & $\begin{array}{c}\text { SD } \\
\text { (P value) }\end{array}$ & $\begin{array}{l}95 \% \mathrm{Cl}, \\
P \text { value }\end{array}$ \\
\hline $\begin{array}{l}\text { Total } \\
\text { (all drugs) }\end{array}$ & 3,683 & -0.05 & $\begin{array}{c}0.29 \\
(0.85) \\
\end{array}$ & $\begin{array}{c}(-0.62 \\
0.52)\end{array}$ & $-\$ 168.21$ & $\begin{array}{c}8.58 \\
(<0.01) \\
\end{array}$ & $\begin{array}{l}(-185.02 \\
-151.4) \\
\end{array}$ & 0.005 & $\begin{array}{c}0.028 \\
(0.852)\end{array}$ & $\begin{array}{c}(-0.05 \\
0.06)\end{array}$ \\
\hline $\begin{array}{l}\text { Aubagio } \\
\text { (teriflunomide, oral) }\end{array}$ & 118 & -0.05 & $\begin{array}{c}0.32 \\
(0.85)\end{array}$ & $\begin{array}{c}(-0.69 \\
0.58)\end{array}$ & $-\$ 134.79$ & $\begin{array}{c}44.03 \\
(<0.01)\end{array}$ & $\begin{array}{l}(-221.08 \\
-48.5)\end{array}$ & 0.004 & $\begin{array}{l}0.024 \\
(0.862)\end{array}$ & $\begin{array}{c}(-0.04 \\
0.05)\end{array}$ \\
\hline $\begin{array}{l}\text { Avonex }^{\mathrm{b}} \\
\text { (interferon beta-1a, IM) }\end{array}$ & 554 & -0.04 & $\begin{array}{c}0.24 \\
(0.85)\end{array}$ & $\begin{array}{l}(-0.5, \\
0.42)\end{array}$ & $-\$ 139.07$ & $\begin{array}{l}21.14 \\
(<0.01)\end{array}$ & $\begin{array}{l}(-180.5 \\
-97.64)\end{array}$ & 0.004 & $\begin{array}{l}0.027 \\
(0.862)\end{array}$ & $\begin{array}{c}(-0.05 \\
0.06)\end{array}$ \\
\hline $\begin{array}{l}\text { Betaseron } \\
\text { (interferon beta-1b, SC) }\end{array}$ & 35 & -0.06 & $\begin{array}{c}0.42 \\
(0.87)\end{array}$ & $\begin{array}{c}(-0.89 \\
0.77)\end{array}$ & $-\$ 122.01$ & $\begin{array}{l}48.22 \\
(0.01)\end{array}$ & $\begin{array}{c}(-216.51 \\
-27.5)\end{array}$ & 0.006 & $\begin{array}{l}0.039 \\
(0.859)\end{array}$ & $\begin{array}{c}(-0.07 \\
0.08)\end{array}$ \\
\hline $\begin{array}{l}\text { Copaxone } \\
\text { (glatiramer acetate, SC) }\end{array}$ & 124 & -0.05 & $\begin{array}{c}0.29 \\
(0.86) \\
\end{array}$ & $\begin{array}{c}(-0.62 \\
0.53)\end{array}$ & $-\$ 211.21$ & $\begin{array}{c}45.23 \\
(<0.01) \\
\end{array}$ & $\begin{array}{l}(-299.86 \\
-122.57) \\
\end{array}$ & 0.019 & $\begin{array}{l}0.098 \\
(0.83)\end{array}$ & $\begin{array}{c}(-0.17 \\
0.21)\end{array}$ \\
\hline $\begin{array}{l}\text { Extavia }^{\mathrm{b}} \\
\text { (interferon beta-1b, SC) }\end{array}$ & 224 & -0.05 & $\begin{array}{c}0.34 \\
(0.86)\end{array}$ & $\begin{array}{c}(-0.72 \\
0.62)\end{array}$ & $-\$ 193.20$ & $\begin{array}{l}42.69 \\
(<0.01)\end{array}$ & $\begin{array}{l}(-276.86 \\
-109.53)\end{array}$ & 0.004 & $\begin{array}{l}0.028 \\
(0.863)\end{array}$ & $\begin{array}{c}(-0.05 \\
0.06)\end{array}$ \\
\hline $\begin{array}{l}\text { Gilenyac } \\
\text { (fingolimod, oral) }\end{array}$ & 872 & -0.06 & $\begin{array}{l}0.37 \\
(0.85)\end{array}$ & $\begin{array}{c}(-0.78 \\
0.66)\end{array}$ & $-\$ 143.26$ & $\begin{array}{l}19.91 \\
(<0.01)\end{array}$ & $\begin{array}{l}(-182.29 \\
-104.24)\end{array}$ & 0.004 & $\begin{array}{l}0.025 \\
(0.856)\end{array}$ & $\begin{array}{c}(-0.05 \\
0.05)\end{array}$ \\
\hline $\begin{array}{l}\text { Glatopa } a^{b, c, d} \\
\text { (glatiramer acetate, SC) }\end{array}$ & 535 & -0.04 & $\begin{array}{c}0.21 \\
(0.85)\end{array}$ & $\begin{array}{c}(-0.44 \\
0.37)\end{array}$ & $-\$ 150.52$ & $\begin{array}{l}18.08 \\
(<0.01)\end{array}$ & $\begin{array}{l}(-185.96 \\
-115.08)\end{array}$ & 0.004 & $\begin{array}{l}0.029 \\
(0.865)\end{array}$ & $\begin{array}{c}(-0.05 \\
0.06)\end{array}$ \\
\hline $\begin{array}{l}\text { Plegridy } \\
\text { (peginterferon beta- } 1 a, S C)\end{array}$ & 6 & -0.03 & $\begin{array}{c}0.21 \\
(0.88)\end{array}$ & $\begin{array}{c}(-0.44 \\
0.38)\end{array}$ & $-\$ 24.04$ & $\begin{array}{l}17.87 \\
(0.18)\end{array}$ & $\begin{array}{l}(-59.07 \\
11)\end{array}$ & 0.006 & $\begin{array}{l}0.048 \\
(0.878)\end{array}$ & $\begin{array}{c}(-0.09 \\
0.1)\end{array}$ \\
\hline $\begin{array}{l}\text { Rebif }^{b} \\
\text { (interferon beta-1a, SC) }\end{array}$ & 370 & -0.07 & $\begin{array}{c}0.41 \\
(0.85)\end{array}$ & $\begin{array}{c}(-0.86 \\
0.73)\end{array}$ & $-\$ 199.43$ & $\begin{array}{l}34.72 \\
(<0.01)\end{array}$ & $\begin{array}{l}(-267.47 \\
-131.38)\end{array}$ & 0.005 & $\begin{array}{l}0.028 \\
(0.851)\end{array}$ & $\begin{array}{c}(-0.05 \\
0.06)\end{array}$ \\
\hline $\begin{array}{l}\text { Tecfidera } \\
\text { (dimethyl fumerate, oral) }\end{array}$ & 845 & -0.05 & $\begin{array}{l}0.29 \\
(0.85)\end{array}$ & $\begin{array}{c}(-0.62 \\
0.52)\end{array}$ & $-\$ 216.71$ & $\begin{array}{l}17.35 \\
(<0.01)\end{array}$ & $\begin{array}{l}(-250.72 \\
-182.7)\end{array}$ & 0.004 & $\begin{array}{l}0.022 \\
(0.856)\end{array}$ & $\begin{array}{c}(-0.04 \\
0.05)\end{array}$ \\
\hline
\end{tabular}

Notes: All cost data in 2018 USD. Total number of claims excludes imputed data (months with no claim) and claims without patient assistance (no price variation). aStandardized to a 30-day supply.

${ }^{\mathrm{D}} \mathrm{KP}$ preferred brand in formulary designations.

'Generic.

$I M=$ intramuscular injection; $K P=$ Kaiser Permanente; $S C=$ subcutaneous injection; $P A P=$ patient assistance program; $P E D=$ price elasticity of demand; USD $=$ US dollar.

therefore be covered by the medical benefit, which would not be captured in pharmaceutical claims. Future analyses should take care in capturing specialty drug use in medical and pharmacy benefit contexts.

In terms of interpreting our statistical analysis, the price variation in our study only goes one way (patients face the charged OOP cost or a lower cost with the use of patient assistance), so we can only comment on patient demand in relation to PAPs and not in relation to any change in OOP price. While we did our best to measure demand by probability of a claim and total days supplied, we were unable to identify patients who failed to start their medication because of prices (ie, noninitiation).
We also could not identify the use of prepaid debit cards or direct-to-patient OOP reimbursement; we omitted the drugs where these practices are most common, but we may have underestimated the magnitude of copay assistance. We did not estimate the impact on health outcomes or nondrug health care use and expenditures; however, this has been analyzed to some extent in other studies. ${ }^{11}$

\section{Conclusions}

As specialty drugs continue to consume a larger portion of our national drug spending, payers and patients must contend with high drug costs. The use of PAPs has the potential 
to significantly decrease patient costs without affecting demand for medication. In light of this, payers may consider embracing PAPs to remove patient financial barriers to necessary medications and use tools other than cost sharing to influence patient consumption of specialty drugs.

\section{DISCLOSURES}

This manuscript was funded in part through a Pre-Doctoral Fellowship in Health Outcomes from the PhRMA Foundation awarded to Brouwer for the completion of her dissertation work. Yeung receives some salary support from Kaiser Permanente. The other authors have nothing to disclose.

\section{REFERENCES}

1. Carroll AE. Even a modest co-payment can cause people to skip drug doses. The New York Times. November 12, 2019. Accessed May 12, 2021. https://www. nytimes.com/2019/11/11/upshot/drugscost-diabetes.html

2. Goodell S, Swartz K. Cost-sharing: effects on spending and outcomes. Robert Woods Johnson Foundation. The Synthesis Project Policy Brief no. 20. December 1, 2010. Accessed May 12, 2021. https:// www.rwjf.org/content/dam/farm/ reports/issue briefs/2010/rwjf402103

3. Choudhry NK, Lee JL, Agnew-Blais J, Corcoran C, Shrank WH. Drug companysponsored patient assistance programs: a viable safety net? Health Aff (Millwood). 2009;28(3):827-34.

4. Dafny L, Ody C, Schmitt M. When discounts raise costs: the effect of copay coupons on generic utilization. Am Econ J Econ Policy. 2017;9(2):91-123.

5. Tribble SJ. The little-known way pharma companies hook people on their costly drugs. Time. December 12, 2018. Accessed May 12, 2021. https://time. com/5477748/pharmaceutical-drug-pricing-direct-reimbursement/
6. Aitken M, Kleinrock M. Medicine use and spending in the U.S.: a review of 2017 and outlook to 2022. IQVIA Institute. April 19, 2018. Accessed May 12, 2021. https://www.iqvia.com/ insights/the-iqvia-institute/reports/ medicine-use-and-spending-in-the-usreview-of-2017-outlook-to-2022

7. Starner CI, Alexander GC, Bowen K, Qiu Y, Wickersham PJ, Gleason PP. Specialty drug coupons lower out-ofpocket costs and may improve adherence at the risk of increasing premiums. Health Aff (Millwood). 2014;33(10):1761-69.

8. Van Nuys K, Joyce G, Ribero R, Goldman DP. A perspective on prescription drug copayment coupons. February 2018. Accessed May 12, 2021. https:// healthpolicy.usc.edu/wp-content/ uploads/2018/02/2018.02_Prescription 20Copay20Coupons20White20Paper Final-2.pdf

9. Ross JS, Kesselheim AS. Prescriptiondrug coupons-no such thing as a free lunch. N Engl J Med. 2013;369(13):1188-89.

10. Dafny LS, Ody CJ, Schmitt MA. Undermining value-based purchasinglessons from the pharmaceutical industry. N Engl J Med. 2016;375(21):2013-15.

11. Groeneweg M, Forrester SH, Arnold B, et al. One-year outcomes of an integrated multiple sclerosis disease management program. J Manag Care Spec Pharm. 2018;24(5):458-63. doi: 10.18553/ jmcp.2018.24.5.458

12. Quan H, Li B, Couris CM, et al. Updating and validating the Charlson comorbidity index and score for risk adjustment in hospital discharge abstracts using data from 6 countries. Am J Epidemiol. 2011;173(6):676-82.

13. Office of Financial Management. Washington data \& research. Estimates of April 1 population by age, sex, race and Hispanic origin. Updated February 2, 2021. Accessed May 19, 2021. https://ofm.wa.gov/ washington-data-research/populationdemographics/population-estimates/ estimates-april-1-population-age-sexrace-and-hispanic-origin
14. Horton NJ, Kleinman KP. Much ado about nothing: a comparison of missing data methods and software to fit incomplete data regression models. Am Stat. 2007;61(1):79-90.

15. Graubard BI, Korn EL. Predictive margins with survey data. Biometrics. 1999;55(2):652-59.

16. Doshi JA, Li P, Ladage VP, Pettit AR, Taylor EA. Impact of cost sharing on specialty drug utilization and outcomes: a review of the evidence and future directions. Am J Manag Care. 2016;22(3):188-97.

17. Criminal Penalties for Acts Involving Federal Health Care Program. Sec. 1128B. [42 U.S.C. 1320a-7b] (a). Accessed May 19, 2021. https://www.ssa.gov/OP_Home/ ssact/title11/1128B.htm

18. Doshi JA, Li P, Pettit AR, Dougherty JS, Flint A, Ladage VP. Reducing out-ofpocket cost barriers to specialty drug use under Medicare Part D: addressing the problem of "too much too soon." Am J Manag Care. 2017;23(3 suppl):S39-S45.

19. Gleason PP, Alexander GC, Starner CI, et al. Health plan utilization and costs of specialty drugs within 4 chronic conditions. J Manag Care Pharm. 2013;19(7):542-48. doi: 10.18553/ jmcp.2013.19.7.542

20. Health Affairs. Prescription drug pricing: pharmacy benefit managers. Health Policy Brief Series 12. September 2017. Accessed May 12, 2021. healthaffairs.org/ do/10.1377/hpb20171409.000178/collectionitem/healthpolicybrief_178.pdf

21. Shao H, Stoecker C, Monnette AM, Shi L. Cost sharing of disease-modifying treatments (DMTs) as policy lever to improve DMTs' access in multiple sclerosis. Value Health. 2018;(9):1083-89.

22. Fendrick AM, Buxbaum J, Westrich K. Supporting consumer access to specialty medications through value-based insurance design. National Pharmaceutical Council. June 10, 2014. Accessed May 12, 2021. https://www.npcnow.org/ publication/supporting-consumeraccess-specialty-medications-throughvalue-based-insurance-design 
23. Zullig LL, Wolf S, Vlastelica L, Shankaran V, Zafar SY. The role of patient financial assistance programs in reducing costs for cancer patients. J Manag Care Spec Pharm. 2017;23(4):407-11. doi: 10.18553/jmcp.2017.23.4.407
24. Andrews M. With federal nod, consumers could lose the boost they get from drug 'coupons'. Kaiser Health News. April 16, 2020. Accessed May 12, 2021. https://khn.org/news/ with-federal-nod-consumers-could-losethe-boost-they-get-from-drug-coupons/
25. Daubresse M, Andersen M, Riggs KR, Alexander GC. Effect of prescription drug coupons on statin utilization and expenditures: a retrospective cohort study. Pharmacotherapy. 2017;37(1):12-24.

26. Howard DH. Drug companies' patientassistance programs-helping patients or profits? N Engl J Med. 2014;371(2):97-99. 